\title{
Effects of Reversible Spinalization on Individual Spinal Neurons
}

\author{
Pavel V. Zelenin, Vladimir F. Lyalka, Li-Ju Hsu, Grigori N. Orlovsky, and Tatiana G. Deliagina \\ Department of Neuroscience, Karolinska Institute, SE-17177, Stockholm, Sweden
}

Postural limb reflexes (PLRs) represent a substantial component of the postural system responsible for stabilization of dorsal-side-up trunk orientation in quadrupeds. Spinalization causes spinal shock, that is a dramatic reduction of extensor tone and spinal reflexes, including PLRs. The goal of our study was to determine changes in activity of spinal interneurons, in particular those mediating PLRs, that is caused by spinalization. For this purpose, in decerebrate rabbits, activity of individual interneurons from L5 was recorded during stimulation causing PLRs under two conditions: (1) when neurons received supraspinal influences and (2) when these influences were temporarily abolished by a cold block of spike propagation in spinal pathways at T12 ("reversible spinalization"; RS). The effect of RS, that is a dramatic reduction of PLRs, was similar to the effect of surgical spinalization. In the examined population of interneurons $(n=199)$, activity of $84 \%$ of them correlated with PLRs, suggesting that they contribute to PLR generation. RS affected differently individual neurons: the mean frequency decreased in $67 \%$ of neurons, increased in $15 \%$, and did not change in $18 \%$. Neurons with different RS effects were differently distributed across the spinal cord: $80 \%$ of inactivated neurons were located in the intermediate area and ventral horn, whereas $50 \%$ of nonaffected neurons were located in the dorsal horn. We found a group of neurons that were coactivated with extensors during PLRs before RS and exhibited a dramatic $(>80 \%)$ decrease in their activity during RS. We suggest that these neurons are responsible for reduction of extensor tone and postural reflexes during spinal shock.

Key words: cold block; postural reflexes; rabbit; spinal cord injury; spinal neurons

\section{Introduction}

In quadrupeds, the dorsal-side-up trunk orientation is maintained during standing due to the activity of the postural system driven mainly by somatosensory information from limb mechanoreceptors (Inglis and Macpherson, 1995; Deliagina et al., 2000, 2006, 2012; Beloozerova et al., 2003; Stapley and Drew, 2009).

In a recent study on decerebrate rabbits (Musienko et al., 2010), we characterized postural limb reflexes (PLRs). It was suggested that PLRs in intact animals contribute substantially to postural reactions (Musienko et al., 2008, 2010; Deliagina et al., 2012). We have found that the spinal cord contains neuronal networks capable of generating PLRs in response to postural perturbations (Musienko et al., 2010). It was shown that activity of many spinal interneurons was closely correlated with PLRs, suggesting their contribution to the generation of these reflexes (Hsu et al., 2012).

The postural system in quadrupeds is strongly affected by spinal cord injury (SCI). Animals with extensive SCI are not able to maintain normal (dorsal-side-up) orientation of their hindquar-

\footnotetext{
Received June 6, 2013; revised 0ct. 22, 2013; accepted 0ct. 27, 2013.

Author contributions: P.V.Z., G.N.O., and T.G.D. designed research; P.V.Z., V.F.L., L.-J.H., and T.G.D. performed research; P.V.Z., V.F.L., and T.G.D. analyzed data; P.V.Z., G.N.O., and T.G.D. wrote the paper.

This work was supported by the National Institutes of Health (Grant R01 NS-064964 to T.G.D.), the Christopher and Dana Reeve Foundation to T.D.G., and the Swedish Research Council (Grant 11554 to T.G.D. and Grant 21076 to P.V.Z.). We thank Dr. Russell Hill for valuable comments on the manuscript.

Correspondence should be addressed to Dr. T.G. Deliagina, Department of Neuroscience, Karolinska Institute, SE-17177, Stockholm, Sweden. E-mail: Tatiana.Deliagina@ki.se.

DOI:10.1523/JNEUROSCI.2394-13.2013

Copyright $\odot 2013$ the authors $\quad 0270-6474 / 13 / 3318987-12 \$ 15.00 / 0$
}

ters and their postural control (including PLRs) does not recover with time (Macpherson et al., 1997; Lyalka et al., 2008, 2009, 2011).

In all studied mammals, including humans, immediate reaction to an extensive SCI is "spinal shock," characterized by a dramatic reduction of extensor tone and most spinal reflexes, including PLRs (Ashby and Verrier, 1975; Brown, 1994; Ditunno et al., 2004; Lyalka et al., 2011). The main reason for spinal shock is loss of supraspinal influences on spinal networks (Ditunno et al., 2004).

Distortions in processing of afferent information by spinal networks caused by spinalization were demonstrated in earlier studies (Sherrington and Sowton, 1915; Liddell, 1934; Eccles and Lundberg, 1959). It was shown that abolition of spinal reflexes after SCI is primarily caused by a large reduction in the excitability of spinal motoneurons (Barnes et al., 1962; Walmsley and Tracey, 1983; Frigon and Rossignol, 2006). Changes in transmission of afferent signals to motoneurons were also shown (Bennet et al., 2004). However, there have been very few studies devoted to the effect of SCI on the activity of individual interneurons mediating different spinal reflexes, and these studies were focused on the effect of partial SCI upon spinal interneurons responding to load receptors (Miller et al., 1995; Chen at al., 2001). The lack of data about changes in the activity of spinal interneurons caused by SCI is mainly due to technical problems: difficulties in recording activity of the same interneurons before and after SCI. However, due to the novel experimental technique (reversible spinalization), which is based on the cold block of signal 
transmission in spinal pathways, we are now able to record individual spinal interneurons under two conditions: (1) when the caudal part of the spinal cord is connected to its rostral part and (2) when it is functionally disconnected. The goal of our study was to determine changes in activity of spinal interneurons, in particular those mediating PLRs, caused by spinalization.

A brief account of this study has been published in abstract form (Deliagina et al., 2009; Lyalka et al., 2012).

\section{Materials and Methods}

Experiments $(N=10)$ were performed on adult male New Zealand rabbits weighing 2.5-3.0 kg. All experiments were conducted with the approval of the local ethical committee (Norra Djurförsöksetiska Nämden) in Stockholm.

Surgical procedures. The animal was injected with propofol (average dose, $10 \mathrm{mg} / \mathrm{kg}$, administrated intravenously) for induction of anesthesia, which was continued on isoflurane $(1.5-2.5 \%)$ delivered in $\mathrm{O}_{2}$. The trachea was cannulated. For all subsequent procedures, the rabbit was positioned in a metal frame, the forequarters were suspended in a hammock, and the head and vertebral column were rigidly fixed in several points (Fig. 1A). The spinal cord was exposed by laminectomy at T11-L1 (for the subsequent mounting of the cooling element for the reversible spinalization), as well as at L4-L6 (for recording of neurons). When positioning the cooling element at T12, the dura mater was left intact. Small holes $\left(\sim 1 \mathrm{~mm}^{2}\right)$ were made in the dura mater at L5 to insert the recording electrodes. Bipolar EMG electrodes were inserted bilaterally into gastrocnemius lateralis (Gast, ankle extensor) and vastus lateralis (Vast, knee extensor).

The animal was then decerebrated at the precollicular-postmammillary level (Musienko et al., 2008). After decerebration, the anesthesia was discontinued. During the experiment, the rectal temperature and mean blood pressure of the animal were continuously monitored and were kept at $37-38^{\circ} \mathrm{C}$ and at $>90 \mathrm{mmHg}$, respectively. Recordings were started not $<1 \mathrm{~h}$ after cessation of anesthesia, when the functional state of the preparation could be characterized by rather stable extensor tonus and pronounced PLRs (see below), which are important attributes of postural activity (Musienko et al., 2008, 2010).

Experimental design. The experimental design is shown in Figure $1 \mathrm{~A}$. The method of induction of PLRs was similar to that described previously (Musienko et al., 2010; Hsu et al., 2012). In short, the hindlimbs of the rabbit were positioned on the horizontal platform, with limb configuration and the interfeet distance similar to that observed in freely standing rabbit. The platform was tilted periodically between two positions, $20^{\circ}$ to the left $(\mathrm{L})$ and $20^{\circ}$ to the right $(\mathrm{R})$, by rotation around the medial axis (Fig. $1 B, C$ ). Because the vertebrate column and pelvis were fixed, tilts of the platform led to flexion/extension movements at the hip, knee, and ankle joints, with a magnitude of $\sim 10^{\circ}$ and close-to-vertical displacements of the distal points of the limbs with an amplitude of $\sim 5 \mathrm{~cm}$ (Fig. 1D). A time trajectory of tilting the platform, and therefore a time trajectory of foot displacement, was trapezoidal with a period of $\sim 6 \mathrm{~s}$ (Fig. $1 E$ ); transition between extreme positions lasted for $\sim 0.5 \mathrm{~s}$ and each extreme position was maintained for $\sim 2.5 \mathrm{~s}$. The tilt angle of the platform was monitored by mechanical sensors, scaled, and recorded as the vertical foot position. The contact forces under the limbs were measured by means of force sensors (Fig. 1B, force).

With this experimental design, the tilt-related somatosensory stimulation was caused by loading and flexion of the limb on the platform side moving up and simultaneous unloading and extension of the opposite limb. This stimulation evoked PLRs (Fig. 2B, before cooling), which included activation of extensors in the flexing limb and increase of its contact force, as well as inactivation of extensors in the extending limb and decrease of its contact force (Musienko et al., 2010).

Reversible spinalization. A technique for blocking the spike propagation in spinal pathways by means of cooling (reversible spinalization) has been adapted from our previous experiments (Deliagina et al., 1983) and those of Walmsley and Tracey (1983), Apkarian et al. (1989), and Miller et al. (1995). The cooler was positioned on the dorsal aspect of T12, as shown schematically in Figure $1 A$. By pumping a cooling agent through the cooler, we decreased the temperature of adjacent tissues to below the threshold for spike propagation (Brooks, 1983), which led to abolition of signal transmission in the spinal pathways under the cooler. Rewarming of the spinal cord led to restoration of spike propagation.

Details of the method are shown in Figure 2A. For better thermoconductance, the cooler was made of a silver plate and its shape replicated the shape of the spinal cord. The cooling agent was pumped through the tube soldered to the plate. To test the efficacy of signal transmission in spinal pathways, two electrodes (made of the stainless steel wire $\mathrm{d}=150 \mu \mathrm{m}$, isolated except for the tip) were inserted into the spinal cord rostral and caudal to the cooler (in segments T11 and L1; Fig. 2A); each electrode was lowered to the depth of $\sim 3 \mathrm{~mm}$ and positioned in the most ventral part of the ventral funiculus. Single current pulses $(0.2 \mathrm{~ms}$, up to $100 \mu \mathrm{A})$ were passed through the rostral electrode (Stim), whereas responses to these pulses in the spinal axons were recorded by means of the caudal electrode (Rec). The temperature on the surface of the cooler was monitored by a miniature thermoresistor.

The procedure of cold block and the effects of cooling are shown in Figure $2 B$. Initially, the cooler had the temperature close to that in surrounding tissues $\left(\sim 35^{\circ} \mathrm{C}\right)$. Then, pumping of a cooling agent $\left(-5^{\circ} \mathrm{C}\right)$ through the cooler was turned on (Fig. $2 B, \mathrm{ON}$ ), and the temperature on the surface of the cooler plate started to decrease from its initial value (Fig. $2 C$, trace Temp); in $40-50 \mathrm{~s}$, the surface temperature reached a plateau $\left(-1^{\circ} \mathrm{C}\right)$. In $\sim 180 \mathrm{~s}$, pumping of the cooling agent was turned off (OFF), and pumping of the warming agent $\left(35^{\circ} \mathrm{C}\right)$ was started instead. This led to a rapid increase in the surface temperature, which returned to its normal value $\left(\sim 35^{\circ} \mathrm{C}\right)$ in $\sim 30 \mathrm{~s}$. Before cooling, stimulation of T11 evoked a response in L1, with a latency of $\sim 0.5 \mathrm{~ms}$ and an amplitude of $\sim 20 \mu \mathrm{V}$ (Fig. $2 B$, asterisk in Resp 1). During cooling, this response 


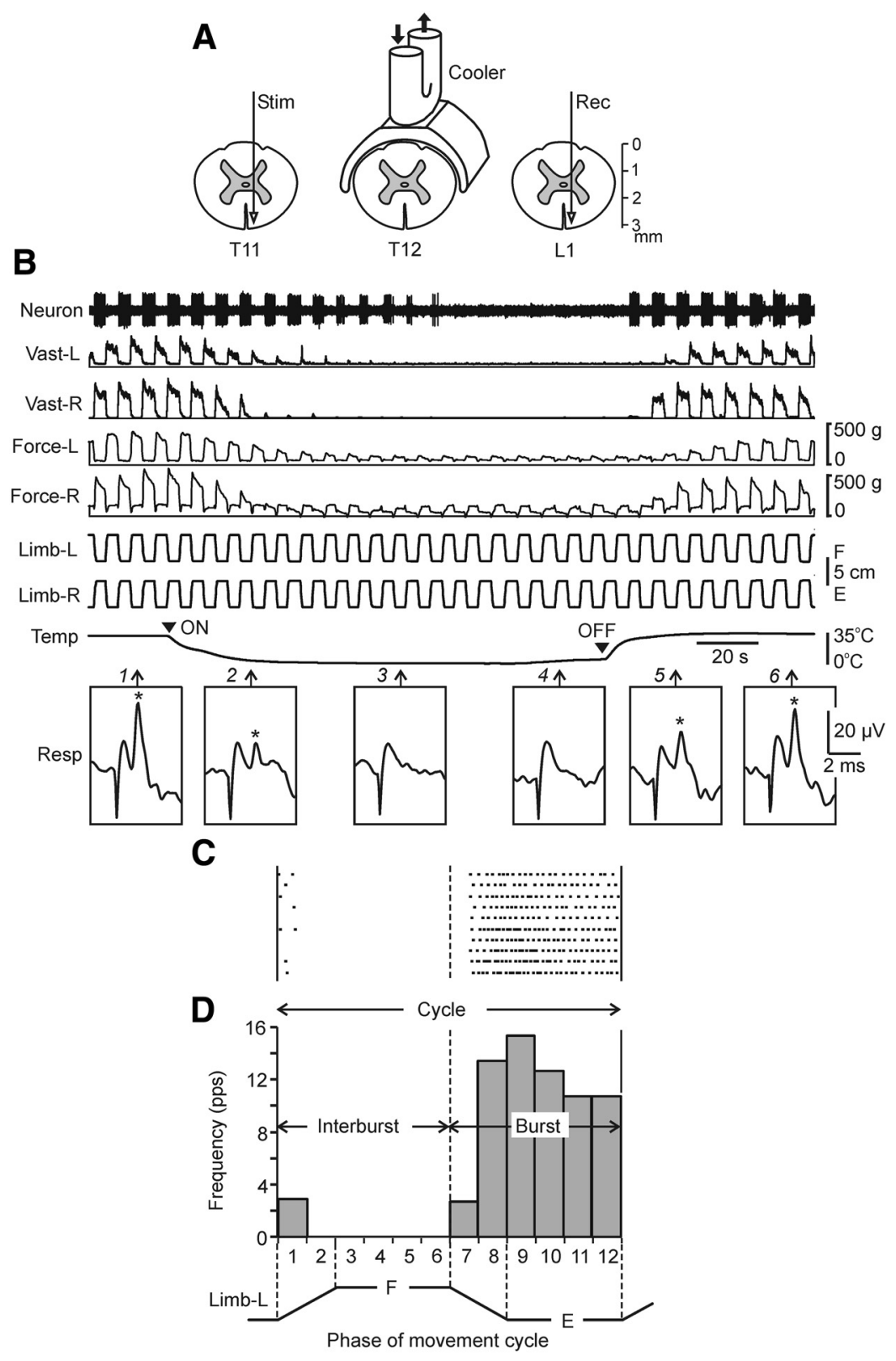

Figure 2. Methods for reversible spinalization $(\boldsymbol{A}, \boldsymbol{B})$ and analysis of neuronal activity $(\boldsymbol{C}, \boldsymbol{D})$. $\boldsymbol{A}$, Position of the cooler on the dorsal surface of the spinal cord, as well as positions of the stimulating (Stim) and recording (Rec) electrodes for monitoring the signal transmission in ventral spinal pathways. Black arrows indicate the flow of cooling agent through the cooler. $\boldsymbol{B}$, Representative example of the effect of reversible spinalization on the signal transmission in ventral spinal pathways, on PLRs, and on the activity of a neuron recorded on the left side of $L$. During this trial, periodical antiphase flexion/extension (F/E) movements of the left and right limbs were continuously performed by tilting the platform; the contact force and the EMG of vastus lateralis (Vast) were recorded bilaterally, along with the activity of the neuron. Trace Temp shows temperature of the cooler; arrowheads $\mathrm{ON}$ and OFF indicate the onset of cooling and the onset of rewarming, respectively. Insets Resp show response at L1 (marked by asterisk) to stimulation of T11 (100 $\mu \mathrm{A}, 0.1 \mathrm{~ms}$ pulse duration) performed at different time points (indicated by arrows $1-6)$. Note that disappearance of responses during cooling (point 3) was correlated with the disappearance of the force, EMG, and neuronal reactions to $\mathrm{F} / \mathrm{E}$ limb movements, whereas reappearance of responses during rewarning (point 5 ) were correlated with restoration of these reactions. $\boldsymbol{C}$, Raster of responses of the neuron shown in $\boldsymbol{B}$ in 10 sequential tilt cycles recorded before cooling. $\boldsymbol{D}$, Histogram of spike activity of this neuron in different parts (1-12) of the tilt cycle. The halves of the cycle with higher and lower neuronal activity were designated as Burst and Interburst periods, respectively.

decreased (Resp 2) and in 60-80 s disappeared (Resp 3 and 4). During warming, the response reappeared (Resp 5) to reach its initial value in $\sim 50 \mathrm{~s}$ (Resp 6). The absence of response at a low temperature suggests that the spike propagation in the tested spinal pathways was blocked. Because these ventral pathways were most remote from the cooler positioned on the dorsal aspect of the spinal cord, one can expect that other pathways (located closer to the cooler) were also blocked. When tested in four experiments, the signal transmission was blocked not later than in $80 \mathrm{~s}$ after the onset of cooling. On this basis, in all other experiments, the rabbit was considered functionally spinalized after $80 \mathrm{~s}$ of cooling.

Recording of neurons and data analysis. Neurons were recorded extracellularly from the spinal segment L5 by means of commercially available varnish-insulated tungsten electrodes (75 $\mu \mathrm{m}$ shaft diameter; FHC). The impedance of the electrodes was 4-7 M $\Omega$. We tended to explore systematically the whole crosssection of the gray matter except for the area of motor nuclei, which is indicated by the dotted line in Figure $4 A-C$ (Portal et al., 1991). The lateral and vertical coordinates of each neuron were marked on the map of the spinal cord cross-section (Shek et al., 1986; Hsu et al., 2012). To escape a bias toward spontaneously active neurons, the search for a neuron was performed during continuous tilting of the platform. Therefore, not only the neurons with spontaneous activity but also those without spontaneous firing (activated by tilt-related somatosensory input from the limbs) were recorded.

Individual neurons were recorded during PLRs caused by platform tilts. This was done under three conditions: (1) before cooling (control), (2) during cooling, and (3) during rewarming. Under each condition, the neuronal activity was recorded, along with the EMGs and ground reaction forces in many (up to 10) sequential tilt cycles.

Signals from the microelectrode (neuronal activity), from the EMG electrodes and from the position and force sensors were amplified; digitized with a sampling frequency of $30 \mathrm{kHz}$ (neuron), $5 \mathrm{kHz}$ (EMGs), and $1 \mathrm{kHz}$ (sensors); and recorded on a computer disk using the data acquisition and analysis system (Power1401/Spike-2; Cambridge Electronic Design). This system also allowed the waveform analysis to discriminate and identify the spikes of a single neuron using the waveform-matching algorithm. Only neurons with stable recordings and spike shape were used for analysis. The EMG signals were rectified and smoothed (time constant, $100 \mathrm{~ms}$ ).

Analysis of neuronal activity is illustrated in Figure 2, $C$ and $D$, for the neuron shown in Figure $2 B$. We considered the activity of all individual neurons in the movement cycle of the ipsilateral limb, because the phase of modulation in the majority of neurons was determined by the tilt-related sensory input from the ipsilateral limb (Hsu et al., 2012, Zelenin et al., 2012). For each individual neuron, the raster of activity in sequential movement cycles was obtained for each of three conditions. The raster for the neuron presented in Figure $2 B$ (a part of recording before cooling) is shown in Figure $2 C$. The cycle was divided into 12 bins; the onset of flexion of the ipsilateral limb was taken as the cycle onset. Bins 1-2 corresponded to flexion of the limb; bins 3-6 to maintenance of the flexed position; bins $7-8$ to extension of the limb; and bins $9-12$ to maintenance of the extended position. The firing frequency in each bin was calculated and 
averaged over the identical bins in all cycles at a given condition and the phase histogram was generated (Fig. 2D).

The following values were used to characterize the activity of a neuron during periodical tilts: $F_{F L E X}$, the mean frequency during ipsilateral limb flexion (average value of bins 1-6); $F_{\text {EXT }}$, the mean frequency during ipsilateral limb extension (average value of bins 7-12); and $F_{\text {MEAN }}$, the mean frequency in the movement cycle (average value of bins 1-12). To evaluate the cyclic changes in frequency, we used a coefficient of modulation: $K_{\mathrm{MOD}}=1-$ $F_{\text {INTER }} / F_{\text {BURST }}$, where $F_{\text {INTER }}$ and $F_{\text {BURST }}$ are the smaller and the larger of the two values, $F_{\text {FLEX }}$ and $F_{\text {EXTEN }}$, respectively.

To characterize the effects of reversible spinalization on the activity of local populations of neurons in different areas of the gray matter, "heat maps" were generated. In these maps, each value of the mean frequency was coded by a specific color (Fig. $6 F-H$ ). To calculate a value in the heat map point with coordinates $(x, y)$, we used measured values of mean frequency for the neurons that were recorded in the vicinity of the point. The measured values were weighted depending on the distance $d$ from $(x, y)$ to the recording point [Gaussian weighting $w(d)=\exp \left(-d^{2} / D^{2}\right)$ with the spatial constant $D=0.4 \mathrm{~mm}]$.

All quantitative data in this study are presented as mean \pm SE. Student's $t$ test was used to characterize the statistical significance when comparing different means; the significance level was set at $p=0.05$.

\section{Results}

\section{Effects of reversible spinalization on} postural limb reflexes

Antiphase flexion/extension movements of two hind limbs caused by platform tilts evoked PLRs, as illustrated in Figure $2 B$ (a part of recording before cooling). Flexion of each limb was accompanied by activation of its extensor muscles (Vast), as well as by an increase in the force developed by the limb. In contrast, extension of the limb caused almost complete inactivation of its extensors and a considerable decrease in the force value. As shown in Figure 2B, the cold block caused almost complete abolition of PLRs. The PLRs fully recovered after rewarming. The same effects were observed with repetitive (up to 50 times) use of the cold block in one experiment.

Effects of the cold block and their reversibility are clearly seen after averaging the PLRs over several sequential cycles (Fig. $3 A$ ). Figure $3 B$ shows the average values of the dynamic and static components of the force response (indicated in Fig. $3 A$ ) recorded before and during the cold block, as well as after rewarming. During the cold block, the force responses (dynamic, $148 \pm 6 \mathrm{~g}$; static, $141 \pm 6 \mathrm{~g}$ ) were $4-5$ times smaller than in control (dynamic, $744 \pm 130 \mathrm{~g}$; static, $474 \pm 73 \mathrm{~g}$ ) and did not differ from the passive force (Psv, $132 \pm 8 \mathrm{~g}$ ) measured after death of the animal. Rewarming resulted in complete restoration of force responses. In our previous study (Musienko et al., 2010), a similar (4-5 times) reduction in the force responses to platform tilts was observed after acute surgical spinalization.

In the cases when the cold block did not cause a complete disappearance of EMG responses, but only their considerable reduction, the phase of these residual responses could differ from
B

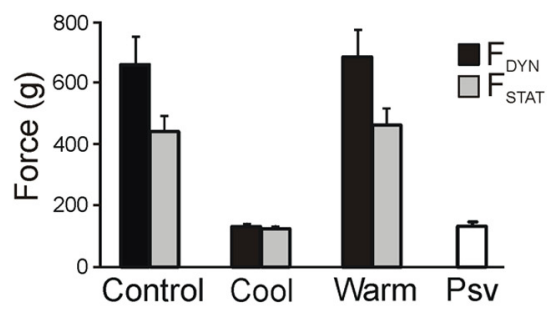

C

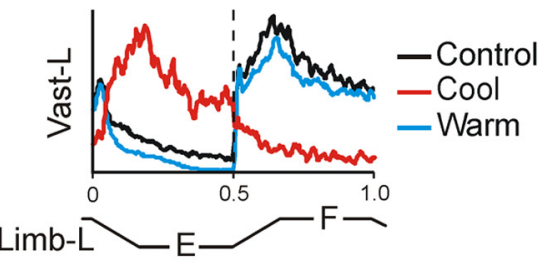

D

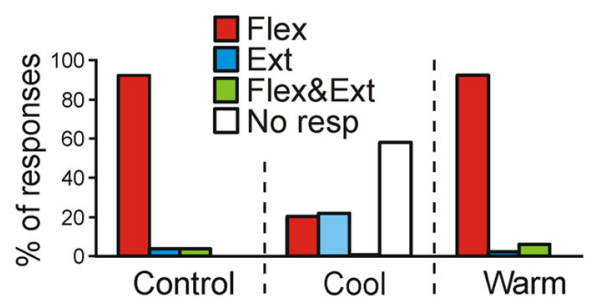

Figure 3. Effects of reversible spinalization on PLRs. A, Example of the left and right Vast and Force responses (elicited by dynamic and static force responses before cooling, during the cold block, after rewarming ( $n=4,16$ tests, averaging over 80 ressive force (Psv, $N=4, n=20$ ). C, Example of the residual incorrectly phased cold block, and after rewarming. Flex, activation with ipsilimb flexion; Ext, activation with limb extensioin; Flex\&Ext, activation with both movements; No resp, EMG not responding. Number of animals and tests: $N=10$ and $n=51$, respectively.

that observed in control, as illustrated in Figure $3 C$ (there was a $30 \times$ increase in EMG amplification for the cold block condition). To characterize residual responses, we used four categories: (1) activation of the muscle with flexion of the ipsilateral limb, (2) activation with limb extension, (3) activation with both flexion and extension, and (4) no response. Figure $3 D$ shows the proportion of different types of responses observed in Vast and Gast before cooling (Control), during the cold block (Cool), and after rewarming (Warm). During the cold block, weak residual responses were observed in $42 \%$ of cases; approximately half of them were caused not by the limb flexion (as in control and after rewarming) but by the limb extension. Similar effects on EMG patterns of PLRs were observed in our previous experiments with acute surgical spinalization (Musienko et al., 2010).

To summarize, the cold block at T12 caused, first, a considerable reduction in the spinal motor output (characterized by the value of PLRs) and, second, changes in the phase of residual responses in a part of cases. Both of these effects were also observed in the rabbits subjected to acute surgical spinalization (Musienko et al., 2010), suggesting that the cold block caused complete spinalization. Full restoration of both the force responses (Fig. 3B) and the patterns of EMG responses (Fig. $3 D$ ) suggested that the spinalization caused by the cold block was reversible.

Activity of spinal neurons before reversible spinalization In total, 199 neurons were recorded during PLRs before reversible spinalization. The overwhelming majority of these neurons 
A F-neurons

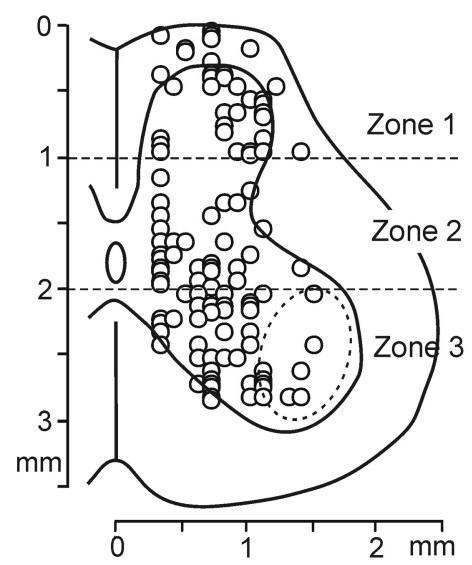

D

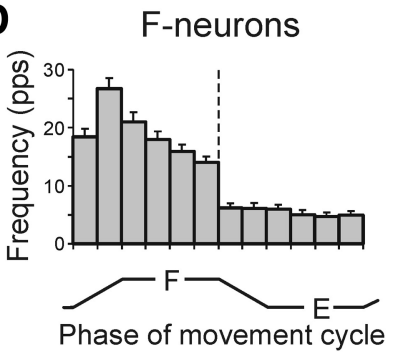

G

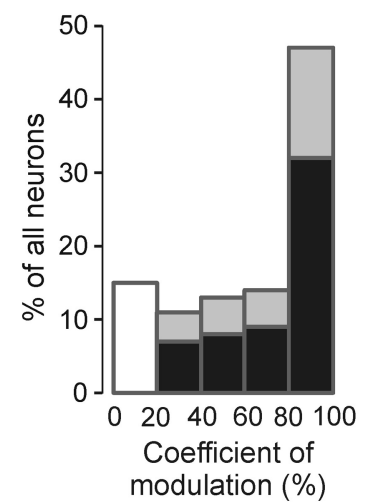

B E-neurons

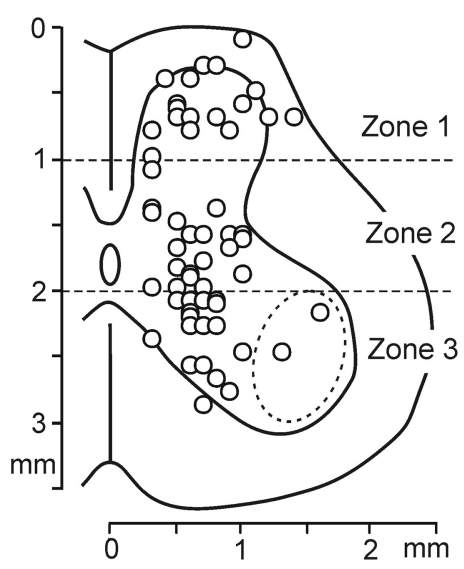

E

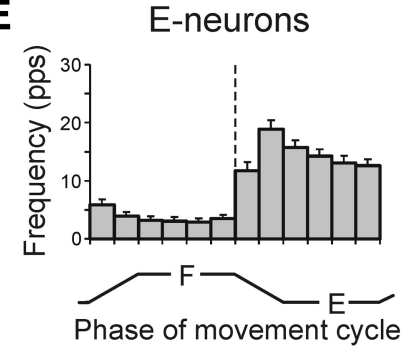

C NM-neurons

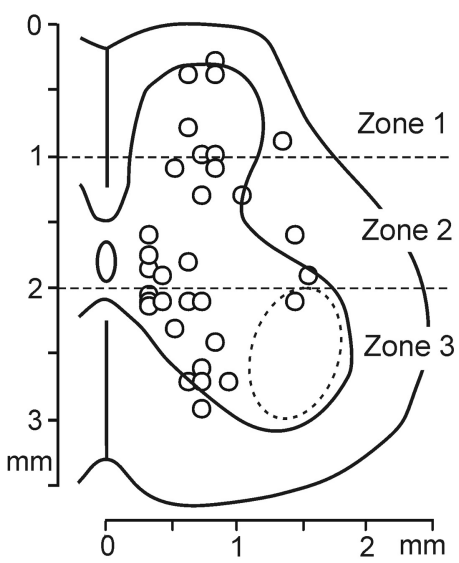

$\mathbf{F}$

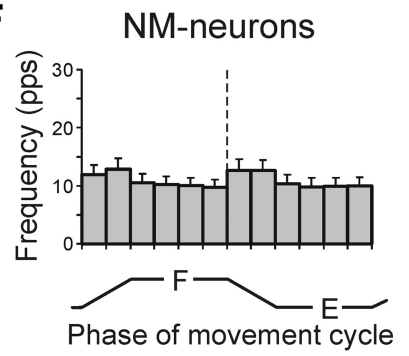

H

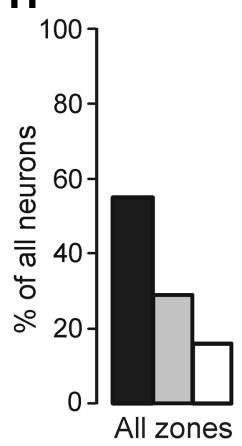

I

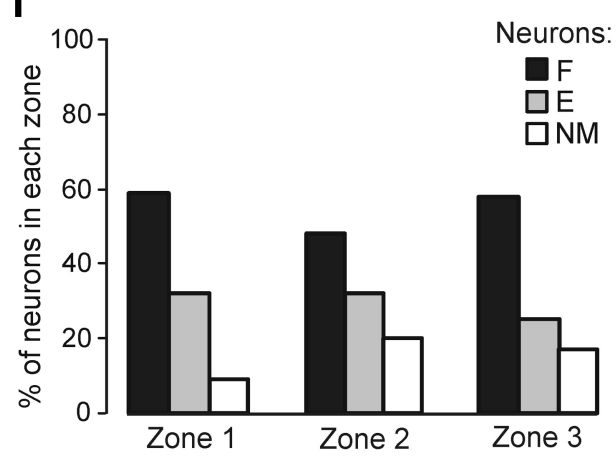

Figure 4. Population characteristics of three groups of spinal neurons (F-, E-, and NM-neurons) recorded before cooling. A-C, Position of F-neurons ( $n=109)$, E-neurons ( $n=58)$, and NM-neurons $(n=32)$ on the cross-section of the spinal cord. An approximate position of motor nuclei is shown by the dotted line. Three zones of the gray matter are indicated: the dorsal (1), intermediate (2), and ventral (3) zones. $\boldsymbol{D}-\boldsymbol{F}$, Average frequency in different phases of the movement cycle of the ipsilimb (mean \pm SE) for F-neurons activated with limb flexion (D), for E-neurons activated with limb extension $(\boldsymbol{E})$, and for NM-neurons not affected by platform tilts $(\boldsymbol{F})$. $\boldsymbol{G}$, Relative number of neurons with different coefficients of modulation. $\boldsymbol{H}, \boldsymbol{I}, \mathbf{R}$ Relative number of $F$-neurons, E-neurons, and NM-neurons in all three zones of the gray matter together $(\boldsymbol{H})$ and in each of the zones separately $(\boldsymbol{I})$. The number of neurons recorded in zones $1-3: n=56, n=63$, and $n=80$, respectively.

were recorded outside of the area of motor nuclei (Fig. $4 A-C$, dotted line) and thus were considered putative interneurons.

To reveal the neurons with activity that was correlated with PLRs, each neuron's mean firing frequency during flexion of the ipsilateral limb $\left(F_{\mathrm{FLEX}}\right)$ and during its extension $\left(F_{\mathrm{EXT}}\right)$ were determined and the coefficient of modulation $\left(K_{\mathrm{MOD}}\right)$ was calculated (see Materials and Methods). Figure $4 G$ shows that the $K_{\mathrm{MOD}}$ value varied considerably between the neurons, from 0 to $100 \%$. We considered the neuron as modulated by tilts (and, therefore, correlated with PLRs) if the $K_{\mathrm{MOD}}$ value was $\geq 20 \%$. In all modulated neurons, the mean frequencies during flexion and extension of the ipsilateral limb were statistically different. Based on this criterion, we found that 167 of 199 recorded neurons (84\%) were modulated, suggesting that they may contribute to the PLR generation, whereas 32 neurons (16\%) were not modulated (Fig. 4G, filled and unfilled bars, respectively).

According to the phase of neuronal response in the tilt cycle of the ipsilateral limb, all modulated neurons were divided into two groups. F-neurons (109 of 199 recorded neurons; 55\%) had a higher frequency in the flexion phase than in the extension phase, whereas E-neurons (58 of 199 recorded neurons; 29\%) had a higher frequency in the extension phase (as the neuron in Fig. $2 B$ ). Neurons of both $\mathrm{F}$ and $\mathrm{E}$ groups, as well as non-modulated (NM) neurons, were found in each individual rabbit in which $>4$ neurons were recorded (Table 1, Control). 
Table 1. Effects of the cold block on the spinal neurons in individual animals

\begin{tabular}{|c|c|c|c|c|c|c|c|c|c|c|c|c|}
\hline \multirow[b]{3}{*}{ Rabbit\# } & \multirow{2}{*}{\multicolumn{3}{|c|}{ Control }} & \multicolumn{9}{|c|}{ Effect of cold block } \\
\hline & & & & \multicolumn{3}{|l|}{ Inhibition } & \multicolumn{3}{|l|}{ Activation } & \multicolumn{3}{|l|}{ No effect } \\
\hline & $\mathrm{F}$ & $E$ & NM & $\mathrm{F}$ & $E$ & NM & $\mathrm{F}$ & $\mathrm{E}$ & NM & $\mathrm{F}$ & $\mathrm{E}$ & NM \\
\hline 2 & $4(67 \%)$ & 0 & $2(33 \%)$ & $3(50 \%)$ & 0 & $1(17 \%)$ & $1(17 \%)$ & 0 & $1(16 \%)$ & 0 & 0 & 0 \\
\hline 3 & $14(45 \%)$ & $12(39 \%)$ & $5(16 \%)$ & $12(39 \%)$ & $7(23 \%)$ & $3(10 \%)$ & $1(3 \%)$ & $1(3 \%)$ & 0 & $1(3 \%)$ & $4(13 \%)$ & $2(6 \%)$ \\
\hline 4 & $3(60 \%)$ & $1(20 \%)$ & $1(20 \%)$ & $3(60 \%)$ & 0 & 0 & 0 & 0 & $1(20 \%)$ & 0 & $1(20 \%)$ & 0 \\
\hline 7 & $6(46 \%)$ & $4(31 \%)$ & $3(23 \%)$ & $3(23 \%)$ & $2(15 \%)$ & $2(15 \%)$ & $2(15 \%)$ & $1(8 \%)$ & 0 & $1(8 \%)$ & $1(8 \%)$ & $1(8 \%)$ \\
\hline 8 & $7(44 \%)$ & $5(31 \%)$ & $4(25 \%)$ & $5(32 \%)$ & $1(6 \%)$ & $4(25 \%)$ & $1(6 \%)$ & $1(6 \%)$ & 0 & $1(6 \%)$ & $3(19 \%)$ & 0 \\
\hline 9 & $5(42 \%)$ & $6(50 \%)$ & $1(8 \%)$ & $5(42 \%)$ & $4(33 \%)$ & 0 & 0 & $2(17 \%)$ & $1(8 \%)$ & 0 & 0 & 0 \\
\hline 10 & $16(55 \%)$ & $8(28 \%)$ & $5(17 \%)$ & $13(45 \%)$ & $4(14 \%)$ & $3(10 \%)$ & $3(10 \%)$ & $2(7 \%)$ & $1(4 \%)$ & 0 & $2(7 \%)$ & $1(3 \%)$ \\
\hline Total & $109(55 \%)$ & $58(29 \%)$ & $32(16 \%)$ & $86(43 \%)$ & $28(14 \%)$ & $20(10 \%)$ & $12(6 \%)$ & $10(5 \%)$ & $7(4 \%)$ & $11(6 \%)$ & $20(10 \%)$ & $5(2 \%)$ \\
\hline
\end{tabular}

Shown are the numbers (percent) of neurons in different groups (F-, E-, and NM-neurons) in control and with different effects of the cold block (inhibition, activation, no effect). Data for individual rabbits (1-10) and for all rabbits (Total) are presented.

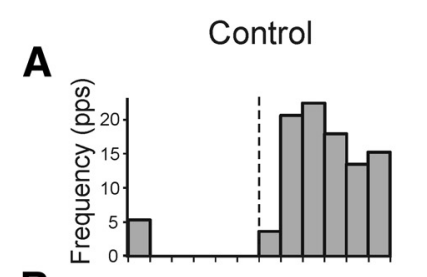

B

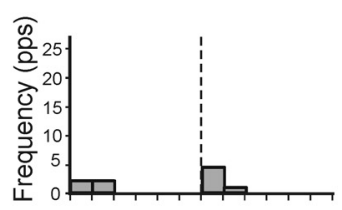

C

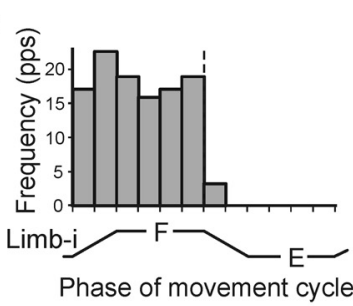

D

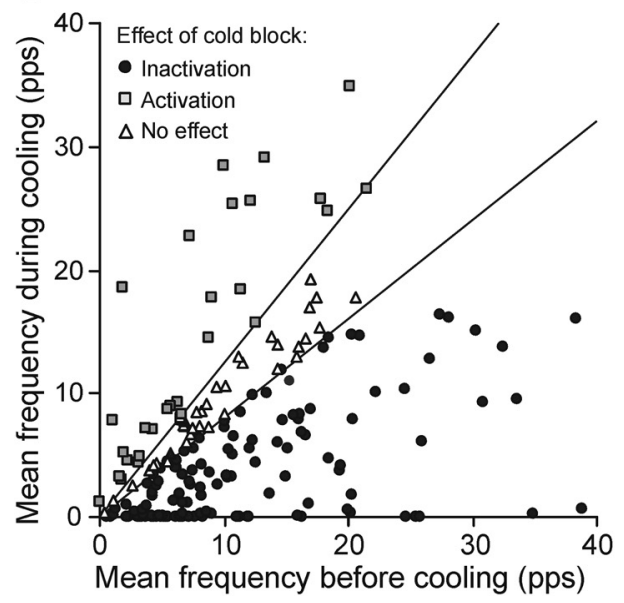

Cold block

Inactivation

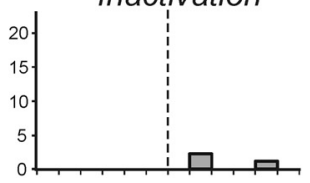

Activation

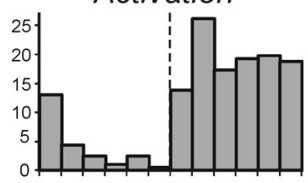

No effect

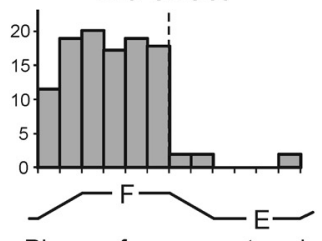

Phase of movement cycle

E

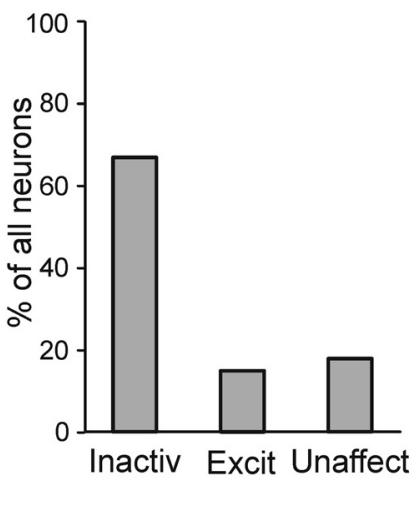

Re-warming
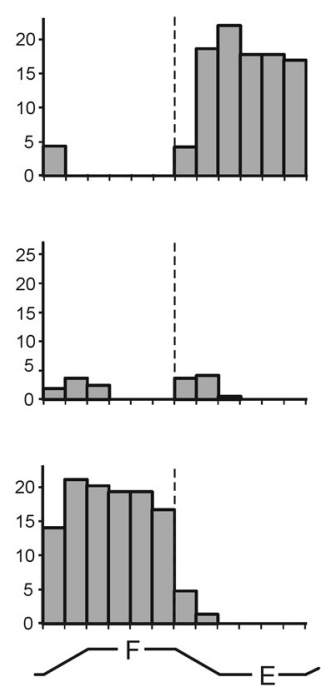

Phase of movement cycle

$\mathbf{F}$

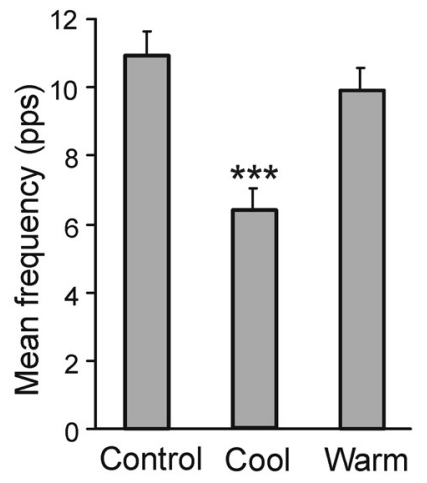

Figure 5. Effects of reversible spinalization on individual spinal neurons. $\boldsymbol{A}-\boldsymbol{C}$, Examples of the cold block effects: inactivation $(\boldsymbol{A})$, activation $(\boldsymbol{B})$, and no effect $(\boldsymbol{C})$. $\boldsymbol{D}$, Mean frequencies of individual neurons ( $n=199)$ under two conditions: before cooling (abscissa) and during cold block (ordinate). The sector delineated the nonaffected neurons (in which the two frequencies differed by $<20 \%$ ). The neurons below the sector were considered inactivated; those above the sector activated. $\boldsymbol{E}$, Proportion of neurons inactivated, activated, and unaffected by the cold block. $\boldsymbol{F}$, Mean frequency of neurons before cooling (Control, $n=199)$, during the cold block (Cool, $n=199)$, and after rewarming (Warm, $n=187) .{ }^{* * *} p<0.001$. 
A Inactivated neurons

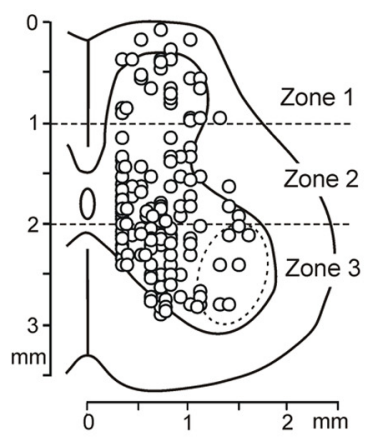

\section{B Activated neurons}

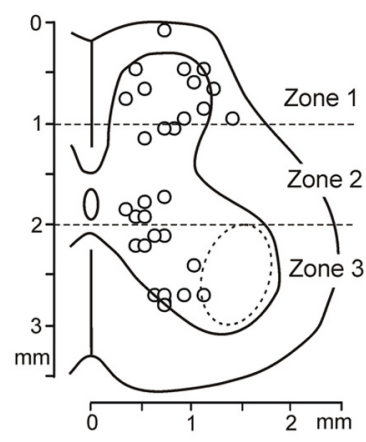

C Unaffected neurons
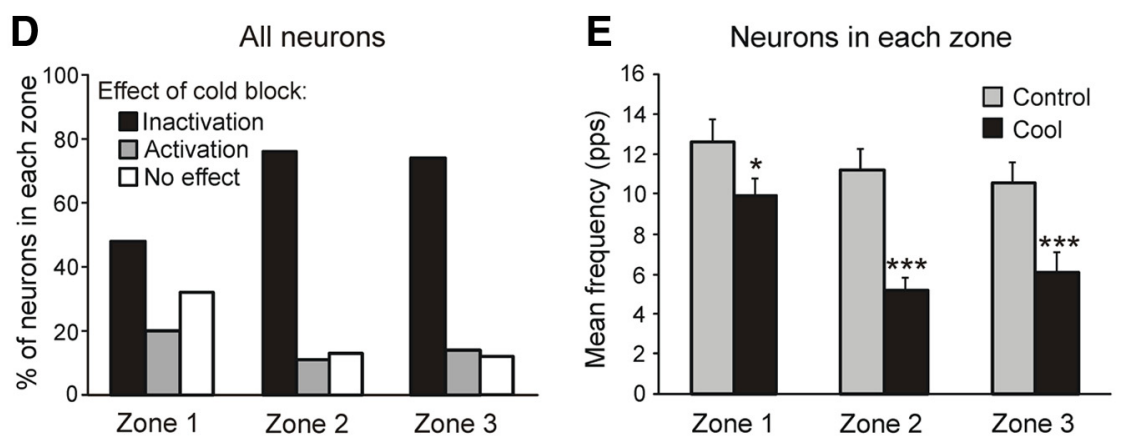

$\mathbf{F}$

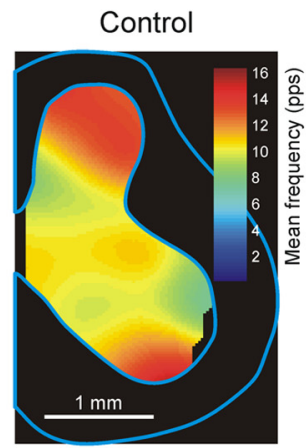

G

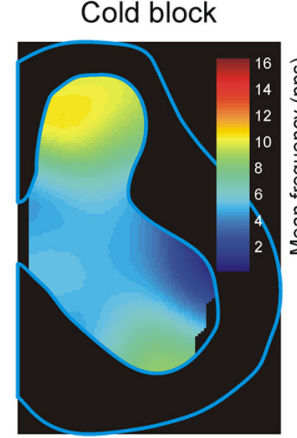

H

Figure 6. Effect of reversible spinalization on the activity of different populations of spinal neurons. $\boldsymbol{A}-\boldsymbol{C}$, Location of inactivated neurons $(n=134 ; \boldsymbol{A})$, activated neurons $(n=29 ; \boldsymbol{B})$, and unaffected neurons $(n=36 ; \boldsymbol{C})$. $\boldsymbol{D}$, Proportion of inactivated, activated, and unaffected neurons in each of the three zones of the gray matter. $E$, Mean frequency of neurons in each of the three zones before cooling (Control) and during the cold block (Cool). ${ }^{*} p<0.05$; ${ }^{* * *} p<0.001 . \boldsymbol{F}-\boldsymbol{H}$, Averaged distribution of neuronal mean frequencies on the cross-section of the spinal cord before cooling $(\boldsymbol{F})$, during the cold block $(\boldsymbol{G})$, and the difference between the two distributions $(\boldsymbol{H})$. The frequency values are presented as a heat map (see Materials and Methods).

Figure 4, $D-F$, and Table 1 (Control) show the average activity in different phases of the tilt cycle for all F-neurons $(D)$, E-neurons $(E)$, and NM-neurons $(F)$. The value of mean frequency $\left(F_{\text {MEAN }}\right)$ in the NM-group $(10.9 \pm 1.4 \mathrm{pps})$ did not differ significantly from those in the F-group (12.2 $\pm 0.9 \mathrm{pps})$ or in the E-group $(9.1 \pm 0.8 \mathrm{pps})$. A small but statistically significant difference between values of mean frequencies in the F- and E-groups was due to significant differences between values of their $F_{\text {BURST }}(19.0 \pm 1.3$ pps vs $14.3 \pm 1.2 \mathrm{pps}$, respectively). The values of $F_{\text {INTER }}$ in the F-group (5.5 $\pm 0.7 \mathrm{pps}$ ) and E-group (3.8 $\pm 0.6 \mathrm{pps})$ did not differ significantly. Although the depth of modulation in individual F- and E-neurons was rather diverse, the majority of neurons in each group were deeply modulated, with $K_{\mathrm{MOD}} \geq 60 \%$ (Fig. $4 G$ ).

Figure $4, A-C$, shows the positions of individual F-neurons $(A)$, E-neurons $(B)$, and NM-neurons $(C)$ on the cross-section of the spinal cord. To characterize the distribution of neurons, we divided the cross-section into three zones (Fig. $4 A-C, 1-3$ ) and

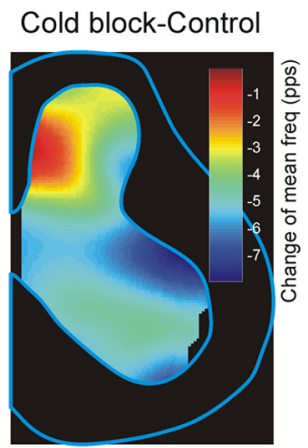

calculated the relative number of neurons of a given group in each of the zones. In general, the proportion of F-neurons, E-neurons, and NM-neurons in the whole population of recorded neurons (Fig. $4 H$ ) was similar to that in each of the zones: the F-group was the largest, the E-group was smaller, and the NM-group was the smallest (Fig. 4I). The proportion of F-neurons was similar in all three zones. The proportion of E-neurons slightly decreased from zone 1 to zone 3 . The finding that neurons of the F- and E-groups were observed in all areas of the gray matter suggests that the modulated neurons within each group do not represent a homogeneous population. Each group could contain premotor interneurons, commissural interneurons, neurons of ascending spinocerebellar tracts, etc. The proportion of NM-neurons was larger in zones 2 and 3 than in zone 1 . The characteristics of the E- and F-neurons obtained in this study were mostly similar to those revealed in our previous studies (Hsu et al., 2012; Zelenin et al., 2012).

\section{Effect of reversible spinalization on spinal neurons}

All 199 recorded neurons were tested under condition of the cold block at T12 (after $80 \mathrm{~s}$ of cooling; see Materials and Methods) using the paradigm shown in Figure $2 B$. Three types of effects of the cold block on the activity of individual neurons were found: inactivation, activation, and no effect. Neurons with these three types of effect were found in most individual animals (Table 1). An effect of inactivation is illustrated in Figure 2B. Before the cold block, this E-neuron was strongly activated during ipsilateral limb extension. With onset of cooling, the activity of the neuron gradually decreased (along with EMG and force responses to tilts) and finally completely disappeared. Rewarming caused restoration of the neuronal activity. Another example of an effect of inactivation is shown in Figure 5A.

An excitatory effect is illustrated in Figure $5 B$. Before the cold block, this neuron was practically inactive. The cold block resulted in activation of the neuron during ipsilimb extension. After rewarming, the activity was very low and similar to that before the cold block. Finally, Figure $5 C$ shows the F-neuron not affected by cooling: this neuron was similarly activated during ipsilimb flexion under all three conditions.

To characterize the effect of cooling on individual neurons, we compared their mean frequencies before and during the cold block (Fig. 5D). In this scatter diagram, the sector around the diagonal delineated the neurons in which the two frequencies differed by $<20 \%$. These neurons $(n=36 ; 18 \%)$ were considered unaffected by the cold block. The majority of neurons $(n=134 ; 67 \%)$ were positioned below the sector; that is, their frequencies were decreased during the cold block; of these 134 neurons, 55 (41\%) were completely inactivated. Fi- 

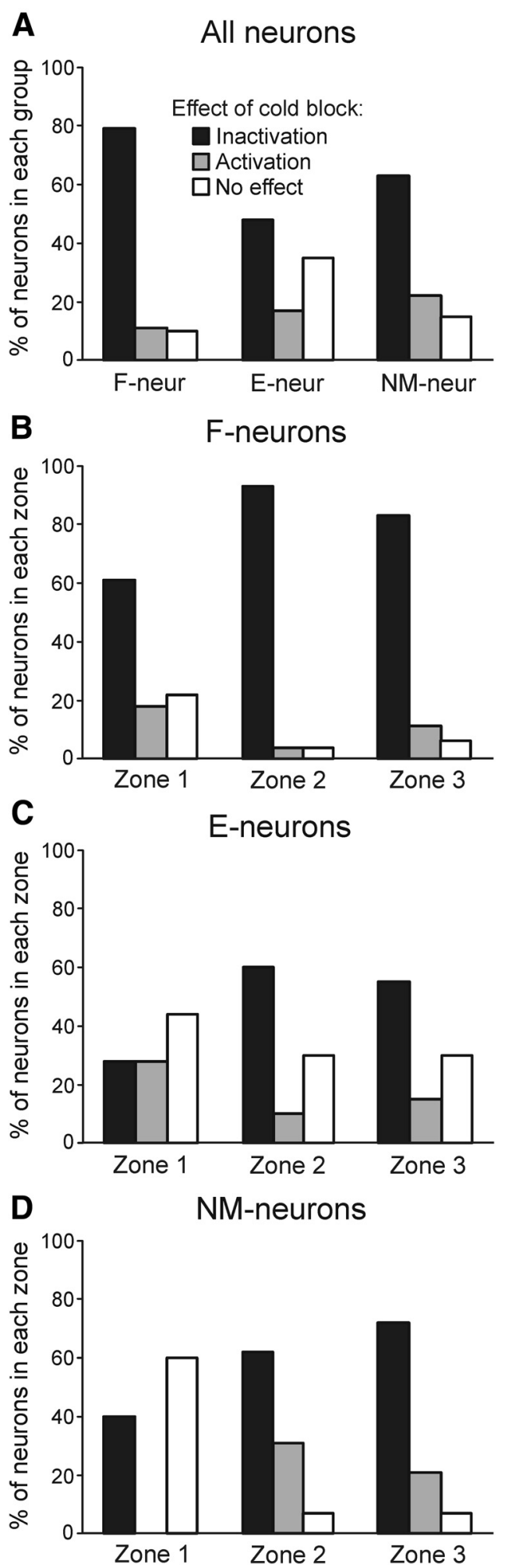

Figure 7. Effects of the reversible spinalization on different groups of spinal neurons. $A$, Proportion of F-, E-, and NM-neurons inactivated, activated, and unaffected by the cold block. $\boldsymbol{B}-\boldsymbol{D}$, Proportion of F-neurons $(\boldsymbol{B})$, E-neurons $(\boldsymbol{C})$, and NM-neurons $(\boldsymbol{D})$ inactivated, activated, and unaffected by cold block in each of three zones of the gray matter. The number of F-, E-, and NM-neurons recorded in zones $1-3: n=33,30,46 ; n=18,20,20 ;$ and $n=5,13,14$, respectively.

nally, 29 neurons (15\%) were positioned above the sector; that is, their frequencies were increased during the cold block. The proportion of neurons with different effects of the cold block is shown in Figure $5 E$.
Due to prevalence of effects of inactivation in individual neurons (Fig. $5 E$ ), a net effect of the cold block was inactivation. Figure $5 F$ shows the mean frequency in the movement cycle (in the tests before cooling, during cooling, and after rewarming), averaged over all tested neurons $(n=199)$. The cold block caused a $42 \%$ reduction in the population activity (from $11.1 \pm 0.6$ to $6.4 \pm 0.5 \mathrm{pps}$ ). After rewarming, the mean frequency increased to $9.7 \pm 0.7$ pps and did not differ statistically from the control value.

A distribution of neurons of different groups (inactivated, activated, and unaffected by cooling) on the cross-section of the spinal cord is shown in Figure $6 A-C$. The effect of cold block was correlated with the neuron position. As described above, we divided the cross-section of the spinal cord into three zones (Fig. $6 A-C, 1-3)$ and calculated the relative number of neurons in different groups for each of the zones. As shown in Figure $6 D$, the proportion of neurons not affected by reversible spinalization was largest in zone $1(32 \%)$. In contrast, in zones 2 and 3, such neurons constituted only $13 \%$ and $12 \%$, respectively. Correspondingly, the proportion of inactivated neurons increased from $48 \%$ in zone 1 to $76 \%$ and $74 \%$ in zones 2 and 3, respectively. As a result of such a distribution, reversible spinalizaton caused a $50 \%$ decrease in the mean frequency of neurons in zone 2 and 3 compared with a $26 \%$ decrease in zone 1 (Fig. $6 E$ ).

To reveal the effect of reversible spinalization on the populations of neurons located in different areas of the gray matter, we used the averaged distribution of neuronal mean frequencies on the cross-section of the spinal cord (see Materials and Methods). As shown in Figure $6 F$, before cooling, the highest activity was exhibited by the neuronal population of the dorsal horn and by the population located in the most ventral area of the ventral horn. The cold block caused a reduction in the activity of neuronal populations across the whole gray matter (Fig. $6 G$ ). This reduction was maximal in the neuronal populations located in the dorsal and most ventral areas of the ventral horn, as well as in the most lateral area of the dorsal horn as shown by subtracting Control from Cold block in Figure $6 \mathrm{H}$. In contrast, the neuronal population located in the medial area of the dorsal horn was practically not affected by reversible spinalization.

The effects of cold block on the three groups of neurons (F-, E-, and NM-neurons) are summarized in Figures 7 and 8 and in Table 1. Figure 7A shows the proportion of neurons with different effects of cooling in each of the three groups of neurons. The F-group included the largest proportion of neurons inactivated by the cold block (79\%) and the E-group included the largest proportion of unaffected neurons (35\%). Each of the three groups contained a small (11-22\%) number of neurons activated by the cold block.

The proportions of F-, E-, and NM-neurons with different effects of cold block located in zones 1-3 are shown in Figure 7, $B-D$, respectively. In each of the three groups, the relative number of neurons not affected by cooling was the largest in zone 1 and the amount of inactivated neurons was the largest in zones 2 and 3. Therefore, the distribution of neurons of each group, which were differently affected by the cold block, along the vertical axis was similar to that found for the whole population of neurons (Fig. 6D).

Figure 8 shows the effects of cooling on the activity of neuronal subpopulations of F-, E- and NM-groups, activated (Fig. $8 A, C, E$ ) and inactivated (Fig. $8 B, D, F$ ) by the cold block. The effects on F-, E-, and NM-neurons within the subpopulation of activated neurons and within the subpopulation of inactivated neurons were similar (Fig. $8 A, B$, respectively). However, the in- 
A
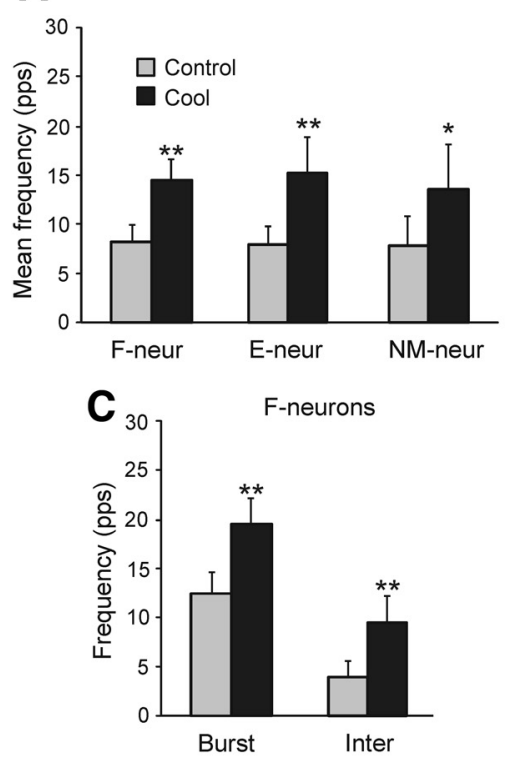

E

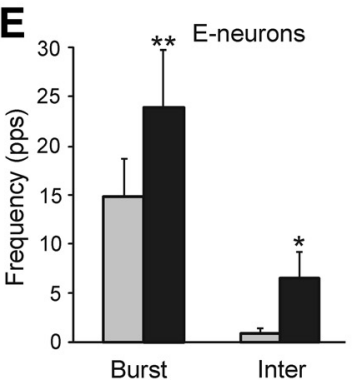

B
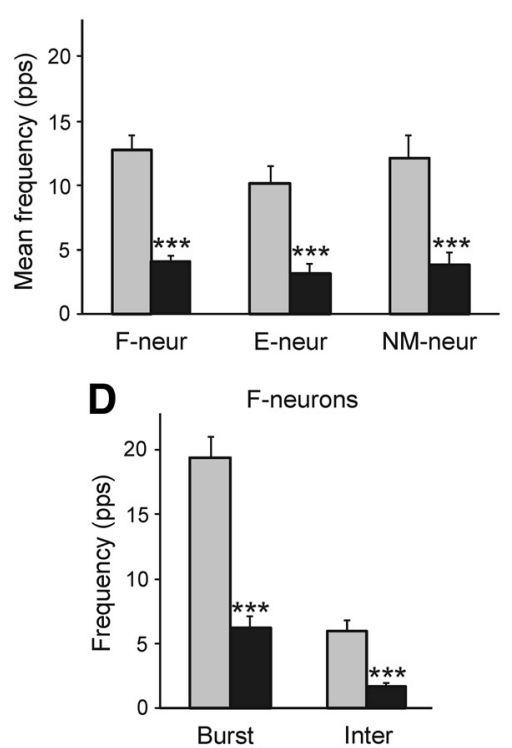

$\mathbf{F}$

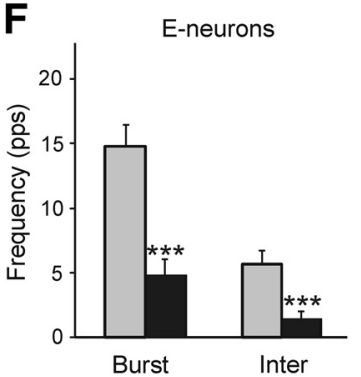

Figure 8. Effects of the reversible spinalization on different characteristics of neuronal discharges. $\boldsymbol{A}, \boldsymbol{B}$, Effect on the mean frequency of activated $(\boldsymbol{A})$ and inactivated $(\boldsymbol{B})$ F-neurons, E-neurons, and NM-neurons. $\boldsymbol{C}-\boldsymbol{F}$, Effect on the mean burst and interburst frequencies of F-neurons $(\boldsymbol{C}, \boldsymbol{D})$ and $\mathrm{E}$-neurons $(\boldsymbol{E}, \boldsymbol{F})$ activated $(\boldsymbol{C}, \boldsymbol{E})$ and inactivated $(\boldsymbol{D}, \boldsymbol{F})$ by the cold block. ${ }^{*} p<0.05 ;{ }^{* *} p<$ $0.01 ;{ }^{* *} p<0.001$.

hibitory effect was stronger than the excitatory one: there was a more than threefold decrease in the mean frequency of inactivated neurons (Fig. $8 B$ ) versus an almost twofold increase in the mean frequency of activated neurons (Fig. $8 A$ ). The increase and decrease in the mean frequency in F- and E-neurons was due to an increase and decrease in both the mean burst and interburst frequencies, respectively (Fig. $8 C-F$ ).

In the overwhelming majority of cases, the cold block did not affect the phase of modulation of the neuron: if the neuron was active during the cold block, then the phase of its peak activity was the same as in control. In only 11 neurons (7\% of modulated neurons) did the cold block abolish the modulation and cause a tonic activity. In six NM-neurons (19\% of NM-neurons) the modulation appeared during the cold block. These neurons (possibly together with F- and E-neurons activated by the cold block) could be responsible for appearance of incorrectly phased EMG responses to tilts observed during reversible spinalization. The number of such neurons is likely to be underestimated in the present study because they could be not active before cooling when we searched for the neurons to be tested by the cold block.

Because spinal shock is characterized by the disappearance of the extensor tone and spinal reflexes, we suggested that the spinal neurons exhibiting the most dramatic $(\geq 80 \%)$ reduction in their mean frequency during the cold block could be responsible for this phenomenon. Such strongly inactivated neurons $(n=61)$ constituted $46 \%$ of the neurons inactivated by the cold block. The population of strongly inactivated neurons contained $66 \%$ of $F$-neurons, $21 \%$ of E-neurons, and $13 \%$ of NM-neurons. Figure 9, $A-C$, shows the positions of strongly inactivated F-neurons, E-neurons, and NMneurons, respectively. One can see that the neurons are distributed over the crosssection, but there are definite areas (indicated by colored lines) with a high density of these neurons. In these areas, $65 \%$ of strongly inactivated F-neurons, 63\% of strongly inactivated E-neurons, and 75\% of strongly inactivated NM-neurons were located.

\section{Discussion}

\section{Effects of cold block on postural limb reflexes}

The main immediate effect of reversible spinalization caused by the cold block of spinal pathways was a dramatic reduction or complete abolition of the tonus and reflex responses in extensor muscles (Figs. 2, 3). This effect was robust and similar to that observed in decerebrate rabbits subjected to surgical spinalization (Musienko et al., 2010). In addition, with reversible spinalization, the small residual EMG responses often had abnormal phasing (Fig. $3 C$ ) that was similar to that after surgical spinalization (Musienko et al., 2010), suggesting that elimination of supraspinal influences caused inactivation of PLRgenerating networks and disinhibition of pathways abnormally processing the tiltrelated sensory information. Similarities between the effects of surgical and reversible spinalization suggest that cooling resulted in the termination of spike transmission in all descending pathways and thus supports the conclusion based on the direct test of conductance in spinal pathways (Fig. 2). These similarities also suggest that surgical interruption of spinal pathways did not produce any additional deficits compared with the cold block.

It was shown that the networks generating PLRs reside in the spinal cord and are driven by sensory input mainly from the ipsilateral limb (Musienko et al., 2010). In spinalized animals, these networks can be activated by tonic stimulation of the spinal cord, suggesting that in intact animals they are activated by tonic supraspinal drive. A small value of spinal PLRs suggests that they are normally supplemented by supraspinal phasic commands. Discontinuation of both tonic and phasic supraspinal influences after spinalization causes dramatic distortions in the network activity manifesting the spinal shock.

\section{Activity of spinal neurons before cold block}

Most neurons recorded in the present study were located outside of the motor nuclei (Fig. $4 A-C$, dotted line) and thus were considered putative interneurons. As in previous studies (Hsu et al., 2012; Zelenin et al., 2012), the activity of most neurons (84\%) was rhythmically modulated by tilts and correlated with PLRs, suggesting their participation in PLR generation. According to 
the phase of their activity in the tilt cycle, all modulated neurons could be divided into two groups: F-neurons were activated during flexion and loading of the ipsilimb (when its extensors were active), whereas E-neurons were activated during extension and unloading of the ipsilimb (when its extensors are not active). Because PLRs are caused by sensory signals coming mainly from the ipsilimb (Musienko et al., 2010) and modulation of the majority of spinal neurons (both F and E) is also determined by sensory input from the ipsilimb (Hsu et al., 2012; Zelenin et al., 2012), one can suggest that at least part of F-neurons and E-neurons participate, respectively, in the excitation and inhibition of extensor motoneurons during PLRs.

\section{Effect of cold block on spinal neurons}

This study has shown for the first time that the activity of individual interneurons is strongly affected by spinalization. The net effect of the cold block was a considerable reduction in the activity of spinal interneurons. The mean frequency of the neurons decreased by $42 \%$ (Fig. $5 F$ ). This result has clearly demonstrated that the spinal networks are not able to maintain a normal level of their activity in the absence of excitatory supraspinal influences, despite the spontaneous activity in some spinal neurons (Baldissera et al., 1981; Jankowska, 2001).

The effects of reversible spinalization in individual neurons were highly diverse: $67 \%$ of neurons were inactivated, $15 \%$ were activated, and $18 \%$ were not affected (Fig. 5E). One can suggest that these groups receive excitatory, inhibitory, or no supraspinal drive, respectively. These drives are provided by supraspinal structures, which are known to exert differential influences on the neurons of various spinal reflex arcs (Eccles and Lundberg, 1959; Engberg et al., 1968a,b,c; Hongo et al., 1969a,b).

The effect of the cold block depended, to some extent, on the position of the neuron. Among the dorsal horn neurons (Fig. $6 A-C$, zone 1 ), the main function of which is processing and integration of sensory information (Baldissera et al., 1981; Jankowska, 2001), $\sim 30 \%$ of neurons were not affected by cooling (Fig. 6D), demonstrating that they were not subjected to supraspinal influences. The majority of neurons from the more ventral areas (zones 2 and 3 ) were inactivated during cooling (Fig. $6 D)$. These neurons constitute the networks generating different motor patterns such as locomotion, PLRs, etc. (Orlovsky et al., 1999; Jankowska, 2001). Therefore, the neurons with such functions are under significant excitatory supraspinal influences and abolition of these influences results in inactivation of neurons.

A small proportion (15\%) of neurons were activated during cooling. Some of them (in which modulation appeared during cooling) could be responsible for the incorrectly phased EMG responses to tilts that appeared after spinalization (Fig. 3C,D; Musienko et al., 2010). A small proportion of neurons activated by RS suggests a relative weakness of supraspinal inhibitory influences compared with excitatory ones. This conclusion differs
B E-neurons

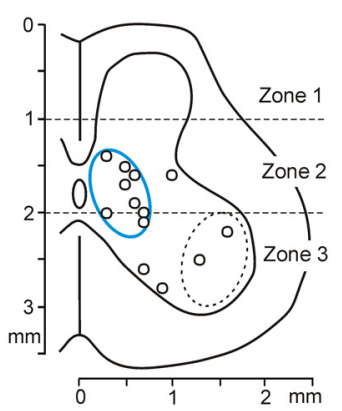

C NM-neurons

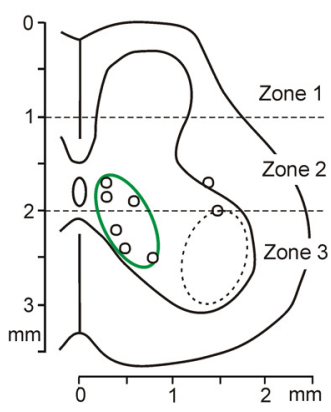

$\mathbf{F}$
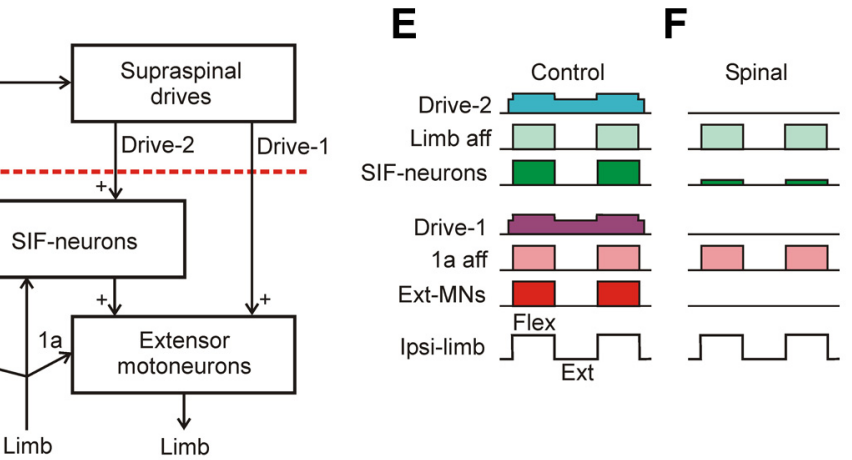

rents

\section{Supraspinal}

drives

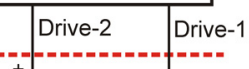

urons

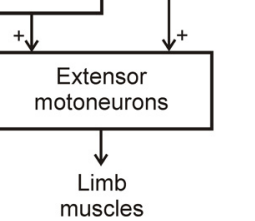

E

$A-C$, Location of strongly inactivated neurons ( $>80 \%$ decrease of frequency) in different groups: F-neurons $(\boldsymbol{A})$, E-neurons $(\boldsymbol{B})$, and NM-neurons $(\boldsymbol{C})$, on the cross section of the spinal cord. Areas with high density of these neurons are demar, blue, and green ellipses, respectively. $\boldsymbol{D}-\boldsymbol{F}$, Presumed neuronal mechanisms underlying the disappearance of PLRs 政 strongly inactivated F-neurons; the red interrupted line shows the level of spinalization. See text for explanations.

from that made in studies on cats decerebrated at the intercollicular level, in which a strong tonic supraspinal inhibition of signal transmission from flexor reflex afferents (FRAs) and Ib afferents to motoneurons was demonstrated and evidence that this inhibition affected spinal interneurons was obtained (Eccles and Lundberg, 1959; Holmqvist and Lundberg, 1959, 1961; Engberg et al., 1965, 1968a,b,c). A possible explanation for this difference could be the different level of decerebration in our experiments (precollicular), with a presumably smaller value of tonic supraspinal inhibition. Another explanation could be that natural stimulation of FRA and $1 \mathrm{~b}$ afferents caused by platform tilts was less efficient than their electrical stimulation.

The effects of the cold block were considerably stronger in F-neurons than in E-neurons. As shown in Figure 7, the proportion of F-neurons inactivated during cooling was significantly larger than the proportion of inactivated E-neurons (79\% vs $48 \%$ ). In contrast, the proportion of unaffected F-neurons was significantly smaller than that of unaffected E-neurons (10\% vs $35 \%$ ). These results suggest that supraspinal drive to F-neurons is considerably stronger than to E-neurons (causing an increased extensor activity in the preparation) and the effects of abolishing this drive are much more prominent. The neurons differently affected by cooling were specifically distributed across the spinal cord (Fig. $7 B-D$ ). The cold block affected both $F_{\text {BURST }}$ and $F_{\text {INTER }}$ (Fig. 8), suggesting that most neurons received supraspinal drive during both phases of the tilt cycle.

An important aim of this study was to reveal a population of spinal interneurons significantly contributing to spinal shock; that is, to inactivation of extensor motoneurons and to dramatic 
reduction of PLRs. Theoretically, all neurons (both modulated and non-modulated), with activity that is strongly affected by spinalization could contribute to spinal shock. In our opinion, however, the most suitable candidates for this role must meet the following requirements: (1) they must be active together with the limb extensors, (2) they must be strongly inactivated during the cold block, and (3) they must activate extensor motoneurons. Spinal neurons that meet the first and second criteria were found in this study; they were located in all three zones of the gray matter, but mostly in the ventromedial area. This group of strongly inactivated F-neurons (named SIF-neurons) is delineated by the red circle in Figure $9 \mathrm{~A}$. Some neurons in this area produce excitation of extensor motoneurons (Jankowska, 1992).

A possible mechanism of spinal shock is shown in Figure 9, $D-F$. Extensor motoneurons receive a direct excitatory drive from supraspinal structures (Drive-1). Another drive is mediated by SIF-neurons (Drive-2). Extensor motoneurons are modulated by sensory input from limb afferents either directly (by la afferents), through SIF-neurons, or due to the long spinosupraspinal loop. Spinalization (Fig. 9D, red interrupted line) deprives the extensor motoneurons of both supraspinal drives, which results in the disappearance of the extensor tone and spinal reflexes (Fig. $9 E, F)$; that is, in spinal shock.

Drives 1 and 2 can be mediated by a number of descending systems (Hongo et al., 1969a,b; Drew and Rossignol, 1990a,b), including the vestibulospinal one, because the galvanic vestibular stimulation causes augmentation of PLRs (Hsu et al., 2012). For motoneurons, one of the sources of supraspinal drive can be the descending axons that release monoamines (serotonin or noradrenaline). Under the effect of this drive, motoneurons become more sensitive to synaptic inputs signaling limb movements (Powers and Binder, 2001; Fedirchuk and Dai, 2004; Hultborn et al., 2003), apparently including inputs eliciting PLRs (Lyalka et al., 2008, 2011; Musienko et al., 2010).

To conclude, in the present study, we have characterized for the first time the changes in activity of individual spinal interneurons from different anatomical and functional groups, which were caused by the reversible spinalization. These changes are responsible for the motor deficit observed in acute spinal subjects (spinal shock). By correlating the effects of different factors (sensory input, spinalization) with the activity of interneurons and extensor motoneurons, we revealed a group of interneurons presumably responsible for the reduction of extensor tone and postural reflexes during spinal shock. The revealed changes in the interneuronal activity also determine the initial status of the spinal networks before their plastic changes occurring in chronic spinal subjects.

\section{References}

Apkarian AV, Hodge CJ Jr, Martin RJ, Stevens RT (1989) A cryogenic device for reversibly blocking transmission through small regions of the spinal cord white matter. J Neurosci Methods 29:93-106. CrossRef Medline

Ashby P, Verrier M (1975) Neurophysiological changes following spinal cord lesions in man. Can J Neurol Sci 2:91-100. Medline

Baldissera F, Hultborn H, Illert M (1981) Integration in spinal neuronal systems. In: Handbook of physiology, Sec 1, The nervous system, Vol 2, Motor control (Brooks VB, ed), pp 509-595. Bethesda, MD: American Physiological Society.

Barnes CD, Joynt RJ, Schottelius BA (1962) Motoneuron resting potentials in spinal shock. Am J Physiol 203:1113-1116. Medline

Beloozerova IN, Zelenin PV, Popova LB, Orlovsky GN, Grillner S, Deliagina TG (2003) Postural control in the rabbit maintaining balance on the tilting platform. J Neurophysiol 90:3783-3793. CrossRef Medline

Bennett DJ, Sanelli L, Cooke CL, Harvey PJ, Gorassini MA (2004) Spastic long-lasting reflexes in the awake rat after sacral spinal cord injury. J Neurophysiol 91:2247-2258. CrossRef Medline

Brooks VB (1983) Study of brain function by local, reversible cooling. Rev Physiol Biochem Pharmacol 95:1-109. CrossRef

Brown P (1994) Pathophysiology of spasticity. J Neurol Neurosurg Psychiatry 57:773-777. CrossRef Medline

Chen D, Theiss RD, Ebersole K, Miller JF, Rymer WZ, Heckman CJ (2001) Spinal interneurons that receive input from muscle afferents are differentially modulated by dorsolateral descending systems. J Neurophysiol 85 : 1005-1008. Medline

Deliagina T, Beloozerova IN, Popova LB, Sirota MG, Swadlow HA, Grant G, Orlovsky GN (2000) Role of different sensory inputs for maintenance of body posture in sitting rat and rabbit. Motor Control 4:439-452. Medline

Deliagina TG, Orlovsky GN, Pavlova GA (1983) The capacity for generation of rhythmic oscillations is distributed in the lumbosacral spinal cord of the cat. Exp Brain Res 53:81-90. Medline

Deliagina TG, Sirota MG, Zelenin PV, Orlovsky GN, Beloozerova IN (2006) Interlimb postural coordination in the standing cat. J Physiol 573:211224. CrossRef Medline

Deliagina TG, Zelenin PV, Karayannidou A, Orlovsky GN (2009) Effect of reversible spinalization on spinal interneurons mediating postural limb reflexes. Soc Neurosci Abstr 35:766.14.

Deliagina TG, Zelenin PV, Orlovsky GN (2012) Physiological and circuit mechanisms of postural control. Curr Opin Neurobiol 22:646-652. CrossRef Medline

Ditunno JF, Little JW, Tessler A, Burns AS (2004) Spinal shock revised: a four-phase model. Spinal Cord 42:383-395. CrossRef Medline

Drew T, Rossignol S (1990a) Functional organisation within the medullary reticular formation of the intact unanaesthetized cat. I. Movements evoked by microstimulation. J Neurophysiol 64:767-781. Medline

Drew T, Rossignol S (1990b) Functional organisation within the medullary reticular formation of the intact unanaesthetized cat. II. Electromyographic activity evoked by microstimulation. J Neurophysiol 64:782-795. Medline

Eccles RM, Lungberg A (1959) Supraspinal control of interneurones mediating spinal reflexes. J Physiol 147:565-584. Medline

Engberg I, Lundberg A, Ryall RW (1965) Reticulospinal inhibition of transmission through interneurones of spinal reflex pathways. Experientia 15: 612-613. Medline

Engberg I, Lundberg A, Ryall RW (1968a) Reticulospinal inhibition of transmission in reflex pathways. J Physiol 194:201-223. Medline

Engberg I, Lundberg A, Ryall RW (1968b) Reticulospinal inhibition of interneurones. J Physiol 194:225-236. Medline

Engberg I, Lundberg A, Ryall RW (1968c) Is the tonic decerebrate inhibition of reflex paths mediated by monoaminergic pathways? Acta Physiol Scand 72:123-133. CrossRef Medline

Fedirchuk B, Dai Y (2004) Monoamines increase the excitability of spinal neurones in the neonatal rat by hyperpolarizing the threshold for action potential production. J Physiol 557:355-361. CrossRef Medline

Frigon A, Rossignol S (2006) Functional plasticity following spinal cord lesions. Prog Brain Res 157:231-260. CrossRef Medline

Holmqvist B, Lundberg A (1959) On the organization of the supraspinal inhibitory control of interneurons of various spinal reflex arcs. Arch Ital Biol 97:340-356.

Holmqvist B, Lundberg A (1961) Differential supraspinal control of synaptic actions evoked by volleys in the flexion reflex afferents in alpha motoneurones. Acta Physiol Scand Suppl 186:1-15. Medline

Hongo T, Jankowska E, Lundberg A (1969a) The rubrospinal tract. I. Effects on alpha-motoneurons innervating hindlimb muscles in cats. Exp Brain Res 7:344-364. Medline

Hongo T, Jankowska E, Lundberg A (1969b) The rubrospinal tract. II. Facilitation of interneuronal transmission in reflex paths to motoneurons. Exp Brain Res 7:365-391. Medline

Hsu LJ, Zelenin PV, Orlovsky GN, Deliagina TG (2012) Effects of galvanic vestibular stimulation on postural limb reflexes and neurons of spinal postural network. J Neurophysiol 108:300-313. CrossRef Medline

Hultborn H, Denton ME, Wienecke J, Nielsen JB (2003) Variable amplification of synaptic input to cat spinal motoneurones by dendritic persistent inward current. J Physiol 552:945-952. CrossRef Medline

Inglis JT, Macpherson JM (1995) Bilateral labyrinthectomy in the cat: effects on the postural response to translation. J Neurophysiol 73:11811191. Medline 
Jankowska E (1992) Interneuronal relay in spinal pathways from proprioceptors. Prog Neurobiol 38:335-378. CrossRef Medline

Jankowska E (2001) Spinal interneuronal systems: identification, multifunctional character and reconfigurations in mammals. J Physiol 533:3140. CrossRef Medline

Liddell EGT (1934) Spinal shock and some features of isolation-alteration of the spinal cord in cats. Brain 57:386-400. CrossRef

Lyalka VF, Musienko PE, Orlovsky GN, Grillner S, Deliagina TG (2008) Effect of intrathecal administration of serotoninergic and noradrenergic drugs on postural performance in rabbits with spinal cord lesions. J Neurophysiol 100:723-732. CrossRef Medline

Lyalka VF, Orlovsky GN, Deliagina TG (2009) Impairment of postural control in rabbits with extensive spinal cord lesions. J Neurophysiol 101: 1932-1940. CrossRef Medline

Lyalka VF, Hsu LJ, Karayannidou A, Zelenin PV, Orlovsky GN, Deliagina TG (2011) Facilitation of postural limb reflexes in spinal rabbits by serotonergic agonist administration, epidural electrical stimulation, and postural training. J Neurophysiol 106:1341-1354. CrossRef Medline

Lyalka VF, Zelenin PV, Hsu L-J, Orlovsky GN, Deliagina TG (2012) Spinal neurons contributing to spinal shock. Soc Neurosci Abstr 38:182.06.

Macpherson JM, Fung J, Jacob R (1997) Postural orientation, equilibrium, and the spinal cord. In: Advances in neurology, Vol 72, Neuronal regeneration, reorganization, and repair (Seil FJ, ed), pp 227-232. Philadelphia: Lippincott Williams and Wilkins.

Miller JF, Paul KD, Jiang B, Rymer WZ, Heckman CJ (1995) Effect of reversible dorsal cold block on the persistence of inhibition generated by spinal reflexes. Exp Brain Res 107:205-214. Medline
Musienko PE, Zelenin PV, Lyalka VF, Orlovsky GN, Deliagina TG (2008) Postural performance in decerebrated rabbit. Behav Brain Res 190:124134. CrossRef Medline

Musienko PE, Zelenin PV, Orlovsky GN, Deliagina TG (2010) Facilitation of postural limb reflexes with epidural stimulation in spinal rabbits. J Neurophysiol 103:1080-1092. CrossRef Medline

Orlovsky GN, Deliagina TG, Grillner S (1999) Neuronal control of locomotion: from mollusc to man. Oxford: Oxford UP.

Portal JJ, Corio M, Viala D (1991) Localization of the lumbar pools of motoneurons which provide hindlimb muscles in the rabbit. Neurosci Lett 124:105-107. CrossRef Medline

Powers RK, Binder MD (2001) Input-output functions of mammalian motoneurons. Rev Physiol Biochem Pharmacol 143:137-263. CrossRef Medline

Shek JW, Wen GY, Wisniewski HM (1986) Atlas of the rabbit brain and spinal cord. New York: Karger.

Sherrington CS, Sowton SC (1915) Observations on reflex responses to single break-shocks. J Physiol 49:331-348. Medline

Stapley PJ, Drew T (2009) The pontomedullary reticular formation contributes to the compensatory postural responses observed following removal of the support surface in the standing cat. J Neurophysiol 101:1334-1350. CrossRef Medline

Walmsley B, Tracey DJ (1983) The effect of transection and cool block of the spinal cord on synaptic transmission between la afferents and motoneurons. Neuroscience 9:445-451. CrossRef Medline

Zelenin PV, Hsu L-J, Lyalka VF, Orlovsky GN, Deliagina TG (2012) Spinal interneurons mediating postural limb reflexes. FENS Forum 6:131.09. 